\title{
Lack of insulin receptors affects the formation of white adipose tissue in mice. A morphometric and ultrastructural analysis
}

\author{
S. Cinti ${ }^{1}$, S. Eberbach ${ }^{1}$, M. Castellucci ${ }^{1}$, D. Accili ${ }^{2}$ \\ ${ }^{1}$ Istituto di Morfologia Umana Normale, Facoltá di Medicina e Chirurgia, Universitá di Ancona, Ancona, Italy \\ ${ }^{2}$ Developmental Endocrinology Branch, National Institute of Child Health and Human Development, \\ National Institutes of Health, Bethesda, Maryland, USA
}

\begin{abstract}
Summary Lack of insulin receptors in mice is associated with near-normal intrauterine growth, unlike patients with leprechaunism, in whom growth deficiency is a prominent clinical feature. Genetic crosses of insulin receptor- and insulin-like growth-factor-1 (IGF-1) receptor-deficient mice indicate, however, that insulin receptors play an important role in late gestational growth, and that absence of growth retardation in insulin receptor-deficient $\left(\mathrm{IR}^{--}\right)$mice may be due to a compensatory increase in IGF-1 receptor levels. In human fetuses, insulin has a paramount role in the generation and maintenance of adipose tissue, as demonstrated by changes associated with genetic and maternally caused fetal hyperinsulinaemia. In the present study, we have investigated whether genetic ablation of insulin receptors affects differentiation and trophism of white adipose tissue, the main target organ for the growth-promoting actions of fetal insulin. Histological, immunohistochemical, and ultrastructural analyses of white dermal adipose tissue
\end{abstract}

were performed in newborn $\mathrm{IR}^{-/-}$mice, as well as normal $\left(\mathrm{IR}^{+/+}\right)$and heterozygous controls ( $\mathrm{IR}^{+/-}$). Stereological measurements revealed a marked decrease of the adipose area in $\mathrm{IR}^{-/-}$mice compared to $\mathrm{IR}^{+/+}$ and $\mathrm{IR}^{+/-}$mice. Fat cell depletion resulted mainly from a reduction of adipocyte volume ( $\sim 90 \%)$, with a small decrease of adipocyte number. Electron microscopy analysis detected all stages of differentiation of the adipocyte precursor in $\mathrm{IR}^{-/}$mice, suggesting that lack of insulin receptors is not associated with selective impairment of the adipocyte differentiation process. These data are consistent with a bi-modal action of fetal insulin receptors, one to mediate embryonic growth in response to IGF-2, and one to mediate adipose cell formation in response to insulin. [Diabetologia (1998) 41: 171-177]

Keywords Diabetes mellitus, adipocyte, genetics, growth, receptors.
Insulin receptors (IRs) mediate insulin action upon target cells [1]. Disorders of IR function are a well established, albeit rare, cause of insulin resistance and diabetes mellitus [2-4]. In mice, targeted ablation of IR expression results in lethal diabetic ketoacidosis [5-7]. Unlike children with homozygous nonsense mutations of the IR gene, $\mathrm{IR}^{-/-}$mice do not develop substantial growth retardation, fasting hypoglycaemia, or signs of hyperandrogenism.

Received: 31 July 1997 and in revised form: 7 October 1997

Corresponding author: D. Accili, M.D., Building 10 Room 10D18, Bethesda, MD 20892, USA
The lack of gross growth retardation in $\mathrm{IR}^{-/-}$mice is an unexpected finding. To understand better the causes of this apparent discrepancy between the human paradigm and the mouse model, we have recently performed genetic crosses of $\mathrm{IR}^{-/}$mice with mice lacking insulin-like growth factor-1 (IGF-1) receptors (IGF-1Rs) and IGF-2 [8]. The results of these experiments indicate that IRs do indeed affect embryonic growth. The growth-promoting actions of IRs occur in response to IGF-2, rather than insulin, binding. The interaction between IRs and IGF-2 plays an important role during the last phase of mouse gestation. Based on these data, we have suggested that the lack of a growth-retarded phenotype in $\mathrm{IR}^{-/}$mice may be due to the shorter duration of mouse gestation 


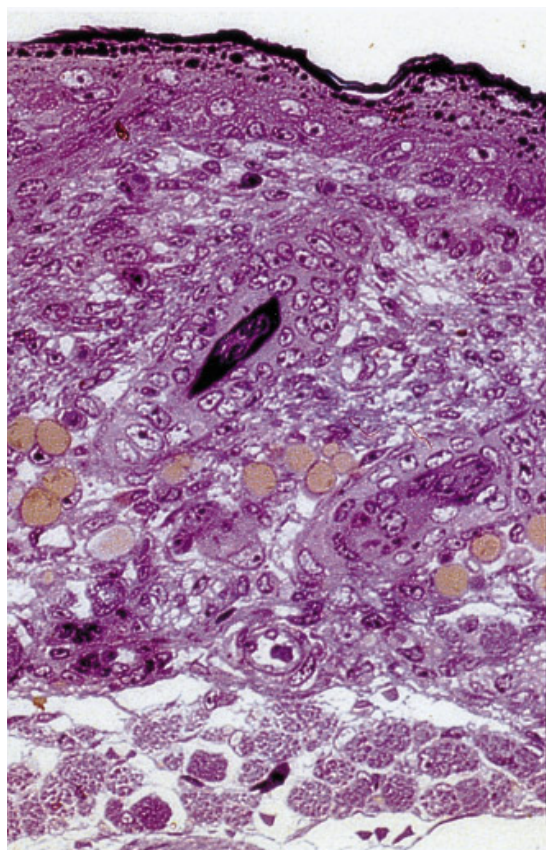

Fig. 1. Histological analysis of dermal sections derived from $\mathrm{IR}^{-/-}$mice and normal controls. Resin embedded skin sections of $\mathrm{IR}^{-/-}$(left panel) and IR ${ }^{+/+}$mice were stained with haematoxylin and eosin and analysed by light microscopy. $\mathrm{IR}^{+1+}$ mice, numerous fat cells can be seen between the lamina basalis and the skin muscle. In $\mathrm{IR}^{-/}$mice, the area occupied by adipose cells is reduced by 50 to $80 \%$. Bar: $10 \mu \mathrm{m}$

compared to human gestation. Furthermore, levels of IGF-1Rs are increased in $\mathrm{IR}^{-/}$mice, providing a further explanation for the near normal size of $\mathrm{IR}^{-/}$ mice [8].

To further support this model, it should be noted that lack of insulin is associated with modest $(\sim 10$ $15 \%$ ) growth retardation in mice [9]. In humans, fetal insulin appears to exert its most important role on fat tissue differentiation and development. Thus, children of diabetic mothers, who are chronically exposed to hyperinsulinaemia, develop macrosomia, due primarily to increased body fat mass $[10,11]$. Likewise, children with persistent hypoglycaemic hyperinsulinism of infancy (PHHI, also known as nesidioblastosis) show dramatic increases in fat body mass [12].

In view of these findings, we have re-visited the question of whether development of fat cells in $\mathrm{IR}^{-/}$ mice occurs normally. Somewhat unexpectedly, Joshi et al. [7] have reported that skin and pericapsular kidney fat are normally represented in a strain of $\mathrm{IR}^{-/}$ mice. A major impediment to these experiments is the scarcity of fat tissue in newborn mice, in which it represents approximately $2 \%$ of total body mass, unlike in humans, in whom it represents approximately $16 \%$ [13]. Thus, to address the role of IRs in adipocyte differentiation, we have examined the ultrastruc-

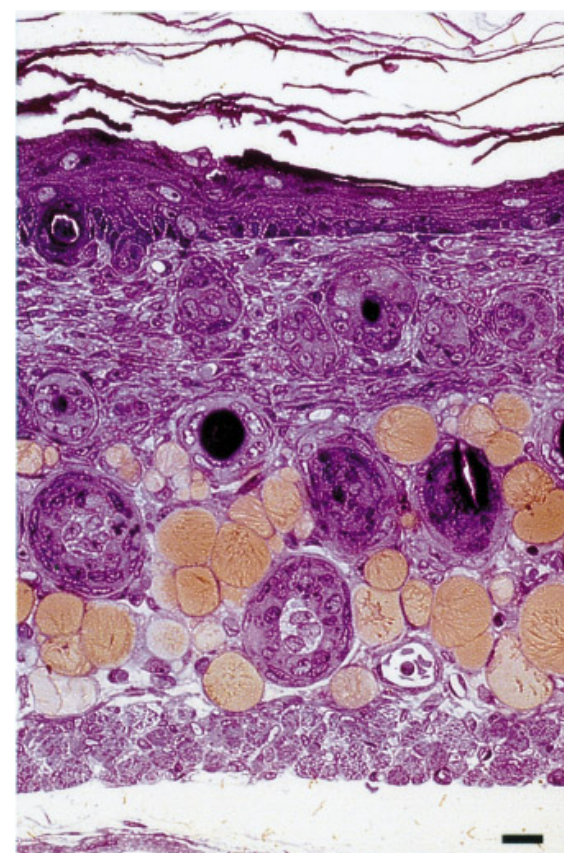

ture of adipocyte precursors in $\mathrm{IR}^{-/}$mice, and performed a morphometric evaluation of dermal adipose tissue. This type of analysis is well suited to detect the various stages of adipocyte development [14], and to quantitate small differences, which may escape different types of analyses, such as studies of biochemical or molecular markers of adipocyte differentiation.

\section{Materials and methods}

Animal husbandry and antibodies. Mice bearing a null allele of the IR have been described previously [5]. A rabbit polyclonal antiserum against the IR $\beta$-subunit was used for immunohistochemistry [5].

Light microscopy. The skin of three different regions was sectioned in cubes of approximately $1 \mathrm{~mm}^{3}$. Skin fragments were isolated from the dorsal thoracic interscapular area near the midline (hereafter referred to as dorsal), from a ventral thoracic area (referred to as thoracic) and from a ventral abdominal area comprised between the sternum and the inguinal margin (referred to as abdominal). Tissues were fixed overnight in a $4 \%$ paraformaldehyde solution in $0.1 \mathrm{~mol} / \mathrm{l}$ phosphate buffered-saline pH 7.4 (Merck, Darmstadt, Germany), dehydrated in a graded series of ethanol and embedded in paraffin. $3 \mu \mathrm{m}$-thick sections were cut and stained with haematoxylin and eosin.

Electron microscopy. Skin fragments of the three regions were fixed in a solution containing $2 \%$ glutaraldehyde, $2 \%$ paraformaldehyde in $0.1 \mathrm{~mol} / 1$ phosphate buffer, $\mathrm{pH} 7.4$ for $4 \mathrm{~h}$ at $4{ }^{\circ} \mathrm{C}$. Specimens were post-fixed in $1 \% \mathrm{OsO}_{4}($ Sigma Chemical Co, St. Louis, Mo., USA), dehydrated in ethanol and embedded in an Epon-Araldite mixture (Multilab Supplies, Fetcham, UK). Ultrathin resin sections were cut with a diamond knife on a Reichert Ultracut E (Reichert, Wien, Austria) and collected on 200-mesh $\mathrm{Cu} / \mathrm{Rh}$ grids (Multilab, Fetcham, UK). Sections were stained with lead citrate and exam- 

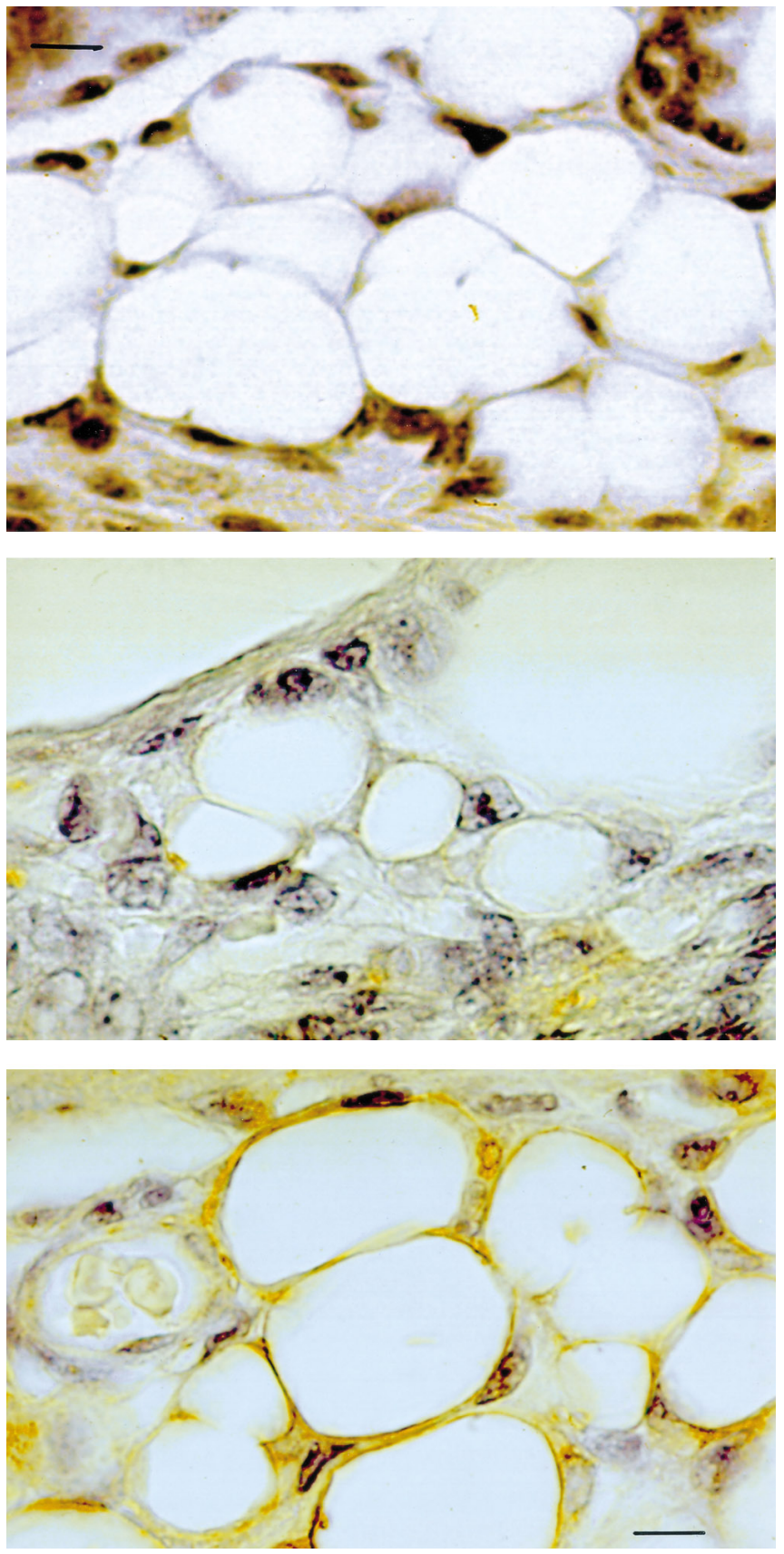

Fig. 2. Immunohistochemical analysis of dermal fat pads in newborn mice. Paraffin-embedded skin sections were incubated with an antiserum directed against the $\beta$-subunit of the IR followed by a biotinylated goat anti-rabbit antibody. Intense staining of the plasma membrane was detected in skin sections of normal mice (bottom panel), but not in $\mathrm{IR}^{-/}$mice (middle panel). Control rabbit serum is shown in the top panel. Bar: $5 \mu \mathrm{m}$

ined with a Philips CM10 electron microscope (Eindhoven, NL). Photomicrographs were taken on Kodak electron microscope 4489 film.

Morphometric analysis. Semi-thin sections $(2 \mu \mathrm{m})$ were obtained with a Reichert microtome Autocut, mounted on glass slides, and stained with toluidine blue. At least five different transverse sections of each region were examined for each ani- mal. We examined a total of 15 independent skin biopsies for each animal, and three animals for each genotype, corresponding to a total of 45 biopsies of each region. After projecting with a Leitz TelePromar 500 Orthoplan light microscope (Leitz, Wetzlar, Germany) at a final magnification of $330 \times$, we focused on an area between the lamina basalis and the skin muscle. The total surface and the area occupied by adipose cells were plotted on the image analyser SEM-IPS Kontron (Munchen, Germany) for automated measurements.

Immunohistochemistry. Immunohistochemistry was performed with the avidin-biotin peroxidase system. We processed $3 \mu \mathrm{m}$-thick de-waxed sections as follows:

1) incubation in $0.3 \% \mathrm{H}_{2} \mathrm{O}_{2}$ in methanol for 30 min to block endogenous peroxidases;

2) pre-incubation with normal goat serum (Vector Laboratories, Burlingame, Calif., USA) at a 1:75 dilution, to reduce non-specific binding;

3) incubation with rabbit anti-IR antibody at a dilution of 1:15,000 in phosphate buffered saline (PBS) overnight at $4{ }^{\circ} \mathrm{C}$; 4) incubation with biotinylated goat anti-rabbit IgG (Vector Laboratories) at a 1:200 dilution in PBS for $30 \mathrm{~min}$;

5) ABC complex (Vector Laboratories) for $1 \mathrm{~h}$;

6) histochemical visualization of peroxidase using 3'3'diaminobenzidine hydrochloride cromogen (DAB, Sigma).

The sections were washed with water and mounted with Entellan (Merck). Micrographs were taken with a Zeiss Photomicroscope on Kodak Ektachrome 64T films.

Statistical analysis. Results are given as mean \pm standard deviation. Statistical analysis was performed using analysis of variance (ANOVA).

\section{Results}

Sections derived from several areas of the skin were analysed by light microscopy (Fig. 1). In IR ${ }^{+/+}$mice (right panel), the dermal adipose tissue was characterized by a well-defined layer of numerous mature adipocytes. In contrast, the dermis of $\mathrm{IR}^{-/}$mice showed a large decrease in the amount of adipose cells (Fig. 1, left panel). None of the other skin lesions observed in humans with similar mutations, i. e. acanthosis nigricans, papillomatosis and hyperkeratosis [15], were observed in $\mathrm{IR}^{-/}$mice. Immunohistochemical studies were performed to determine whether IRs are expressed in dermal adipose cells, using an antibody against the receptor's $\beta$-subunit (Fig. 2). In $\mathrm{IR}^{+/+}$mice, intense staining of the plasma membrane was observed (Fig. 2, lower panel), whereas in $\mathrm{IR}^{-/}$mice no specific staining was detected (Fig.2, middle panel). Staining with control serum did not reveal any immunoreactivity (Fig. 2, upper panel).

To quantitate the differences observed between $\mathrm{IR}^{+/+}$and $\mathrm{IR}^{-/}$mice, morphometric studies were performed on skin biopsies derived from several different areas (Table 1). In dorsal areas of $\mathrm{IR}^{-/}$mice, the total surface occupied by adipose cells was $41 \%$ of that measured in $\mathrm{IR}^{+1+}$ mice $(p=\mathrm{NS}$ by one fac- 

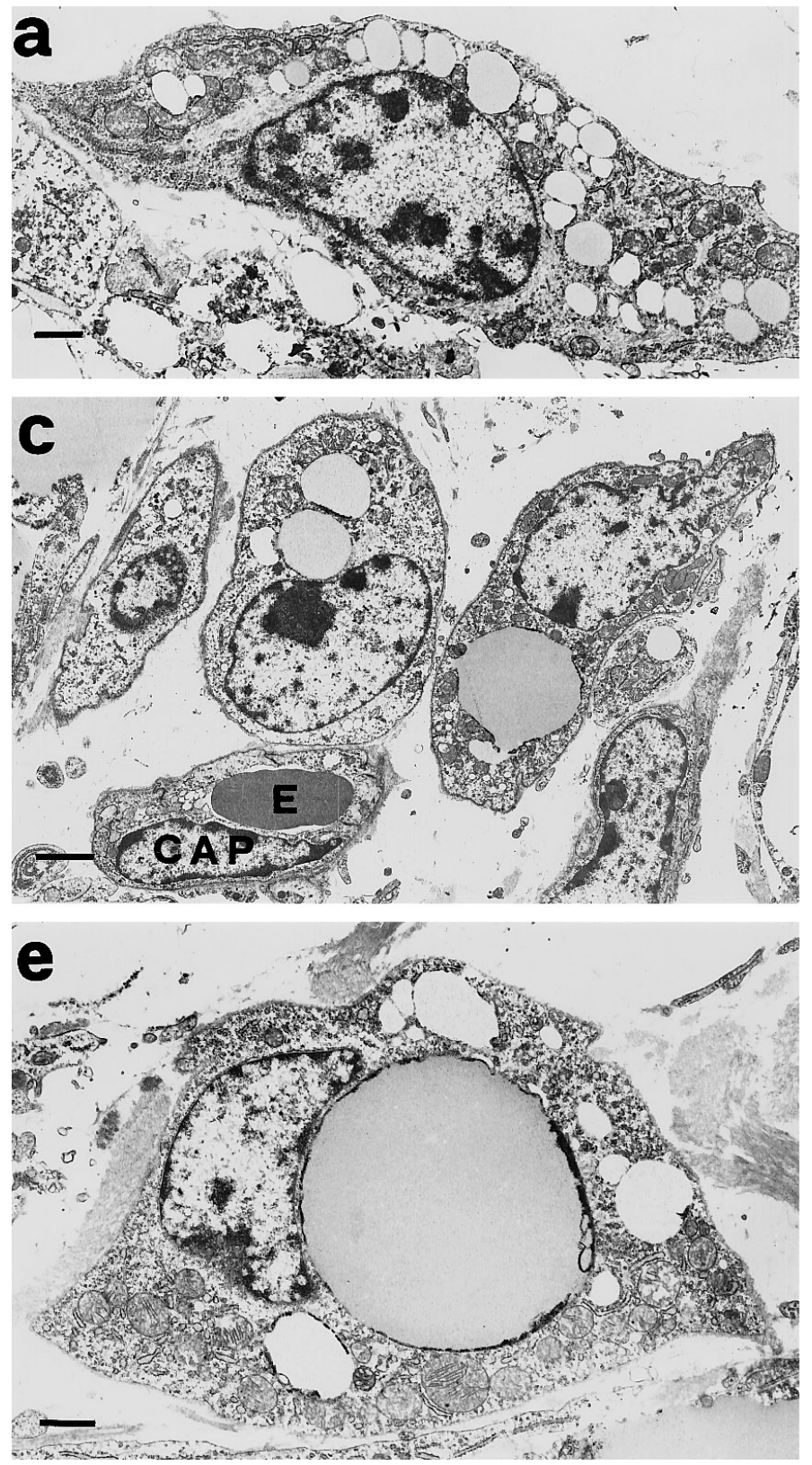

Fig. 3 a-f. Electron microscopy analysis of white adipose tissue of $\mathrm{IR}^{-/}$and $\mathrm{IR}^{+/+}$mice. Skin sections were prepared for electron microscopy as described. Panels a, c, and e: $\mathrm{IR}^{-/-}$mice; panels $\mathbf{b}, \mathbf{d}$, and $\mathbf{f}$ : IR ${ }^{+/+}$mice. $\mathbf{a}-\mathbf{b}$ : early stages of differentiation; c-d: intermediate multilocular stage of differentiation; e-f: intermediate mostly multilocular stage of differentiation; CAP: capillaries containing erythrocytes (E). Bars in $\mathbf{a}, \mathbf{b}, \mathbf{e}$ : $1 \mu \mathrm{m}$; bars in c, $\mathbf{d}, \mathbf{f}: 2 \mu \mathrm{m}$

tor ANOVA). In abdominal areas, the adipose surface was decreased to $19 \%$ of normal $(p<0.05$ by one factor ANOVA), and in thoracic areas to $17 \%$ of normal ( $p<0.05$ by one factor ANOVA). In mice heterozygous for the IR mutation $\left(\mathrm{IR}^{+/}\right)$, the decrease in the amount of adipose tissue was intermediate between the $\mathrm{IR}^{+/+}$and $\mathrm{IR}^{-/}$mice in all areas
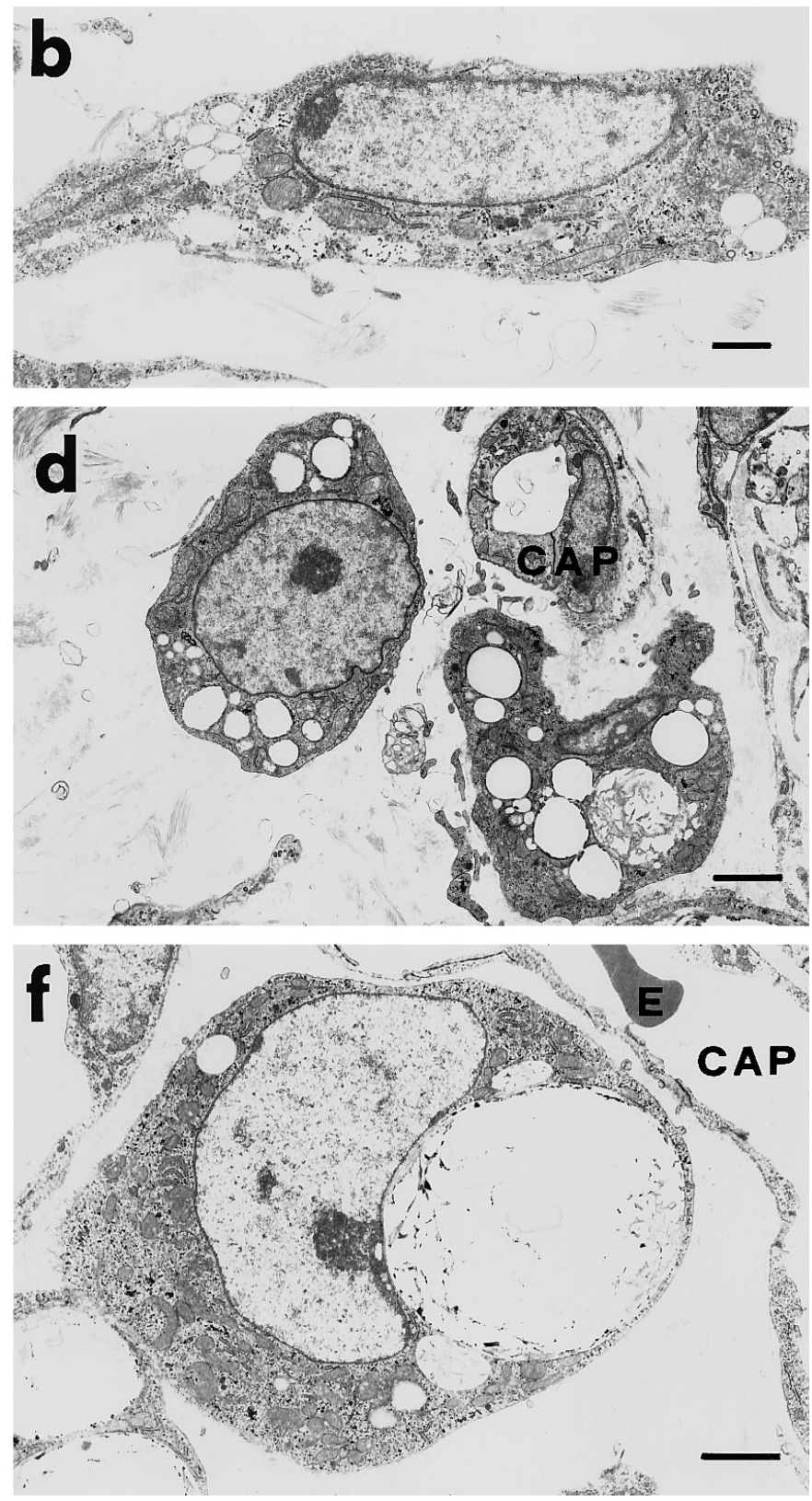

analysed. A decrease in the surface of individual fat cells accounted for approximately $90 \%$ of the observed reduction in adipose area (Table 2), with a small decrease of adipocyte cell number.

Next, we examined the stages of adipocyte differentiation by electron microscopy (Fig. 3). Cells at various differentiation stages were found in both $\mathrm{IR}^{+1+}$ and $\mathrm{IR}^{-1-}$ mice. An early stage of differentiation of the pre-adipocyte is represented by spindle-shaped cells with small cytoplasmic lipid droplets located on both sides of the nucleus. This early differentiation stage is mostly found in peri-capillary areas [16-20]. Accordingly, similar cells were found in mice of both genotypes (Fig. $3 \mathrm{a}$ and b). Later stages are represented by mid-differentiation cells of ovoidal shape, with increased amounts of cytoplasmic lipids and glycogen granules (Fig. 3, c-f), and by fully differentiated cells, 
Table 1. Summary of morphometric measurements on dermal fat tissue derived from mice of different genotypes

\begin{tabular}{llll}
\hline Genotype & Dorsal & Abdominal & Thoracic \\
\hline $\mathrm{IR}^{+/+}$ & 100 & 100 & 100 \\
& $(22.39 \pm 4.69)$ & $(9.98 \pm 2.12)$ & $(13.59 \pm 3.18)$ \\
$\mathrm{IR}^{+/}(\% \mathrm{WT})$ & 66 & 51 & $50^{\mathrm{a}}$ \\
& $(14.73 \pm 7.24)$ & $(5.11 \pm 3.86)$ & $(6.52 \pm 4.15)$ \\
$\mathrm{IR}^{-/-}(\% \mathrm{WT})$ & 41 & $19^{\mathrm{a}}$ & $17^{\mathrm{a}}$ \\
& $(9.24 \pm 4.22)$ & $(1.85 \pm 1.12)$ & $(2.08 \pm 1.52)$ \\
\hline
\end{tabular}

Values are expressed as $\%$ of $\mathrm{IR}^{+/+}$. Values in parentheses indicate the percentage of fat tissue compared to total dermal tissue examined. ${ }^{\mathrm{a}} p<0.05$ by ANOVA

Table 2. Summary of morphometric measurements on individual adipose cells from mice of different genotypes

\begin{tabular}{llll}
\hline Genotype & $\begin{array}{l}\text { Adipocyte } \\
\text { surface } \\
\left(\mu \mathrm{m}^{2}\right)\end{array}$ & $\begin{array}{l}\text { Adipocyte } \\
\text { diameter } \\
(\mu \mathrm{m})\end{array}$ & $\begin{array}{l}\text { Adipocyte cell } \\
\text { density } \\
\left(\mathrm{mm}^{2}\right)\end{array}$ \\
\hline $\mathrm{IR}^{+/+}$ & 100 & 100 & 100 \\
& $(245.1 \pm 14.0)$ & $(17.6 \pm 0.5)$ & $(886.7 \pm 138.3)$ \\
$\mathrm{IR}^{+/-}(\% \mathrm{WT})$ & 71 & 83 & 90 \\
& $(173.9 \pm 56.3)$ & $(14.6 \pm 2.6)$ & $(805.9 \pm 205.3)$ \\
$\mathrm{IR}^{-/-}(\% \mathrm{WT})$ & $48^{\mathrm{a}}$ & 68 & 83 \\
& $(117.9 \pm 43.0)$ & $(12.1 \pm 2.2)$ & $(743.7 \pm 69.8)$ \\
\hline
\end{tabular}

Values are expressed as \% of $\mathrm{IR}^{+/+}$. Values reflect measurements from dorsal subcutaneous tissue. ${ }^{a} p<0.05$ by ANOVA

of spherical form, with a flattened nucleus and large lipid accumulation in the cytoplasm (not shown). Cell types belonging to each of the different stages were found in $\mathrm{IR}^{-1-}$ mice, suggesting that the hypotrophied dermal fat does not result from an intrinsic defect of a step in the adipose differentiation programme.

Ultrastructural analysis also revealed numerous droplets of lipid-like structures in the lumen of capillaries of $\mathrm{IR}^{-/-}$mice, but not in IR $\mathrm{IR}^{+/+}$mice (Fig. 4, upper and lower panels). The size of these droplets ranged from 1200 to $4500 \AA$ (mean $\pm \mathrm{SD}=2100$ $\pm 92 \AA$ ). They probably represent chylomicron remnants [21] that failed to be cleared from the circulation by the liver. In some sections, these droplets appear to impinge on the membrane of the endothelial cell of arterioles, and to give rise to formations protruding into the lumen (Fig. 5).

\section{Discussion}

We have previously shown that inactivation of IR in mice does not cause the same growth retardation as is normally observed in humans with similar mutations [6]. Subsequent studies have indicated that mice lacking both IRs and IGF-1Rs are more severely growth retarded than mice lacking either receptor alone, suggesting that IRs do play an important role
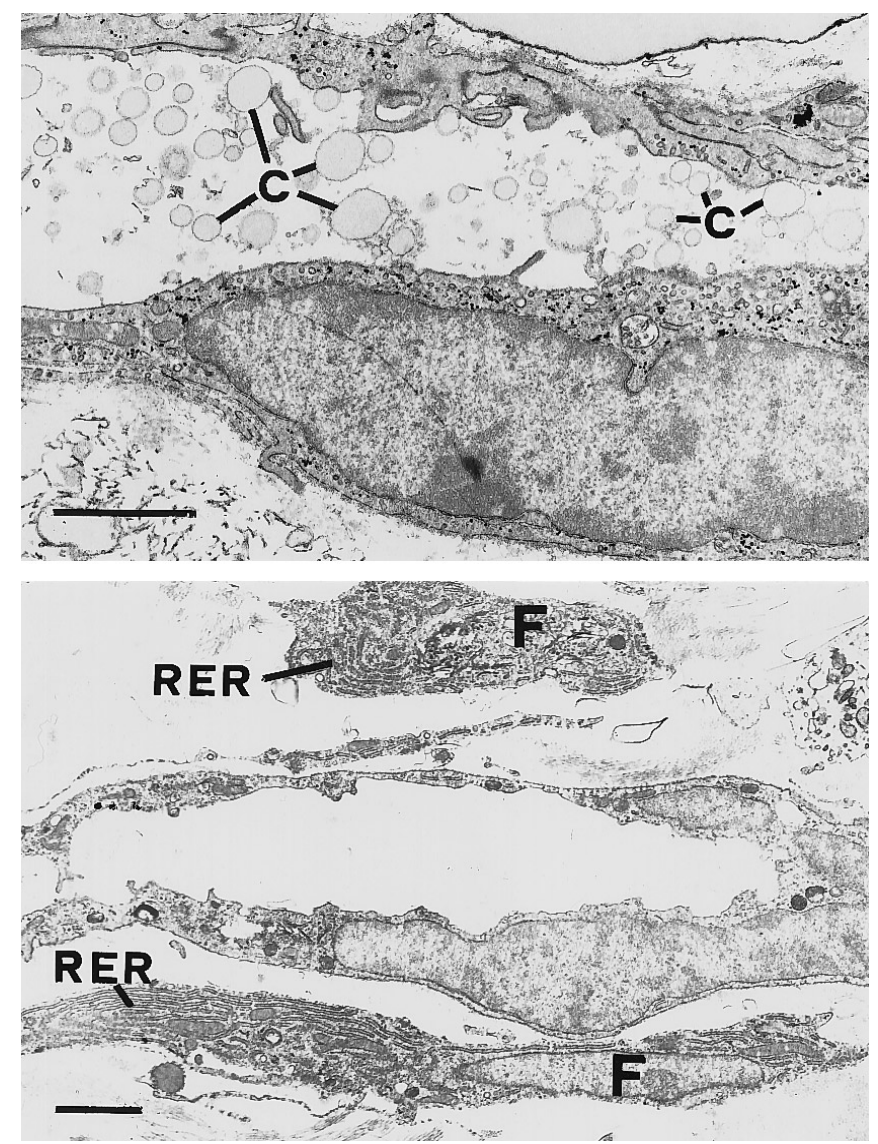

Fig. 4. Electron microscopy analysis of white adipose tissue of $\mathrm{IR}^{-/}$and $\mathrm{IR}^{+/+}$mice. Longitudinal sections of capillaries showing chylomicron remnants $(\mathrm{C})$ in vessels of $\mathrm{IR}^{-/-}$mice. $\mathrm{F}$ : fibroblasts showing abundant rough endoplasmic reticulum (RER). Bars: top $1 \mu \mathrm{m}$, bottom $2 \mu \mathrm{m}$

in promoting growth of mouse embryos. IR-mediated growth occurs predominantly in late gestation in response to IGF-2 binding [8]. Evidence derived from targeted mutagenesis of the two mouse insulin genes suggests that insulin plays a small role in mouse embryonic growth [9]. Interestingly, activation of IRs in response to IGF-2 seems to have a broader range of effects to stimulate embryonic growth than insulin binding to IRs $[8,22]$. In humans, fetal insulin acts primarily at the level of the adipocyte to stimulate growth. For example, macrosomia associated with fetal hyperinsulinism is largely the result of increased fat body mass [12, 23, 24]. Thus, it would be predicted that fat cell mass should be impaired in the absence of IRs.

To address this question, we have analysed dermal white adipose tissue in $\mathrm{IR}^{-/-}$mice. The findings of the present study are consistent with in vitro data indicating that IRs are not required for progression through a specific step of the adipogenic process. For example, in cultures of 3T3-L1 cells, IGF-1 is about two orders of magnitude more potent than insulin in stimulating terminal differentiation $[25,26]$. On the other 


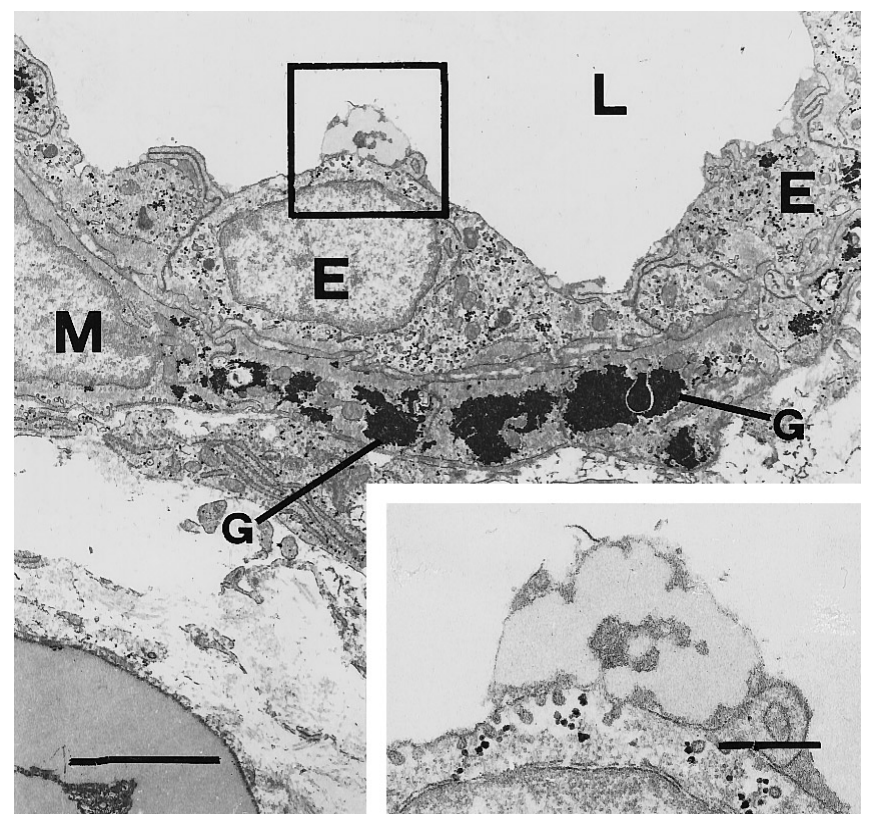

Fig.5. Electron microscopy of dermal adipose tissue of $\mathrm{IR}^{-1}$ mouse showing a transverse section of an arteriole. An aggregate of chylomicron remnants impinges on the membrane of an endothelial cell (framed area). Inset: enlargement of the framed area. E: endothelial cells. M: muscle cells rich in glycogen particles $(\mathrm{G})$. L: lumen of the arteriole. Bar: $2 \mu \mathrm{m}$. Inset bar: $0.45 \mu \mathrm{m}$

hand, IGF-1 seems to be unable to substitute for insulin's actions on terminally differentiated adipocytes. In this respect it is interesting to note that IGF-1 can exert hypoglycaemic, but not lipogenic effects, in $\mathrm{IR}^{-/}$mice [27]. In a different model, we have previously shown that partial inactivation of the IR gene in 3T3-L1 cells is associated with impaired adipocyte differentiation, and that this defect can be reversed by over-expression of IRs [28].

Interestingly, not all dermal areas are equally susceptible to insulin resistance; for example, the decrease of fat content in abdominal and thoracic areas is more marked than in dorsal areas. It remains to be determined whether the different sensitivity of different areas can be explained by the presence of other paracrine factors acting in concert with insulin to favour fat deposition in specific areas. Our findings differ from those of Joshi et al. [7], who have reported that subcutaneous and peri-renal fat tissue in $\mathrm{IR}^{-/}$ mice is normal. These differences could be due to the different genetic backgrounds of the two strains, or to the different analysis techniques.

The abnormalities of lipid metabolism in mice lacking IRs are particularly striking. The findings are similar to the "chylomicronaemia syndrome", observed in patients with diabetic ketoacidosis and underlying lipid storage diseases, such as familial hypertriglyceridaemia, or chylomicron remnant syndrome [29]. The clinical picture in $\mathrm{IR}^{-/-}$mice can be explained by the physiologic state of ketosis of the new- born rodent, due to the fat-rich diet ( $\sim 70 \%$ longand medium-chain fatty acids) [30]. Furthermore, insulin levels fall at birth in rodents, while glucagon levels rise, to favour fatty acid oxidation and generation of ketone bodies as the primary energy source for the developing brain [31].

In summary, morphological and ultrastructural analyses of white fat tissue in $\mathrm{IR}^{-1-}$ mice indicate that IRs are required to mediate the trophic effects of insulin on white adipose cells. The derivation of pre-adipocyte cells from embryos of $\mathrm{IR}^{-/}$mice should provide a useful model to investigate further the signalling pathways involved in this process.

Acknowledgements. This work was partially supported by a research grant of the American Diabetes Association and by a generous gift of Sigma Tau Corp. to D. A. We thank Kristina Rother (NIH) for her critical reading of the manuscript.

\section{References}

1. Cheatham B, Kahn CR (1995) Insulin action and the insulin signaling network. Endocr Rev 16: 117-142

2. Accili D (1995) Molecular defects of the insulin receptor gene. Diabetes Metab Rev 11: 47-62

3. Moller DE, Flier JS (1991) Insulin resistance-mechanisms, syndromes, and implications. N Engl J Med 325: 938-948

4. Taylor SI (1992) Lilly Lecture: molecular mechanisms of insulin resistance. Lessons from patients with mutations in the insulin-receptor gene. Diabetes 41: 1473-1490

5. Accili D, Drago J, Lee EJ, et al. (1996) Early neonatal death in mice homozygous for a null allele of the insulin receptor gene. Nat Genet 12: 106-109

6. Accili D (1997) Insulin receptor knock-out mice. Trends Endocrinol Metab 8: 101-104

7. Joshi RL, Lamothe B, Cordonnier N, et al. (1996) Targeted disruption of the insulin receptor gene in the mouse results in neonatal lethality. EMBO J 15: 1542-1547

8. Louvi A, Accili D, Efstratiadis A (1997) Growth-promoting interaction of IGF-II with the insulin receptor during mouse embryonic development. Dev Biol: 189: 33-48

9. Duvillie B, Cordonnier N, Deltour L, et al. (1997) Phenotypic alterations in insulin-deficient mutant mice. Proc Natl Acad Sci USA 94: 5137-5140

10. Naeye RL (1965) Infants of diabetic mothers: a quantitative, morphologic study. Pediatrics 35: 980-988

11. Fee JM, Weil WB (1963) Body composition of infants of diabetic mothers by direct analysis. Annals New York Acad Sci 110: 869-897

12. Milner RDG (1996) Nesidioblastosis unravelled. Arch Dis Child 74: 369-372

13. Widdowson EM (1950) Chemical composition of newly born mammals. Nature 166: 626-628

14. Weibel E (1979) Stereological methods, practical methods for biological morphometry. Academic Press, London

15. Roth SI, Schedewie HK, Herzberg VK, et al. (1981) Cutaneous manifestations of leprechaunism. Arch Dermatol 117: 531-535

16. Napolitano L (1963) The differentiation of white adipose tissue: an electron microscopic study. J Cell Biol 18: 663673

17. Slavin B (1979) Fine structural studies on white adipocyte differentiation. Anat Rec 195: 63-72 
18. Cinti S, Cigolini M, Bosello O, Bjorntorp P (1984) A morphological study of the adipocyte precursor. J Submicrosc Cytol 16: 243-251

19. Ailhaud G, Dani C, Gaillard D, Grimaldi P, Negrel R (1992) Critical steps and hormonal control of adipose cell differentiation. Pediatr Adolesc Med 2: 115-124

20. Ailhaud G, Grimaldi P, Negrel R (1994) Hormonal regulation of adipose differentiation. Trends Endocrinol Metab 5: $132-136$

21. Glickman RM, Sabesin SM (1994) Lipoprotein Metabolism. In: Arias IM, Boyer JL, Fausto $\mathrm{N}$ et al. (eds). The liver: biology and pathobiology. Raven Press, New York pp. 391-402

22. Morrione A, Valentinis B, Xu S-Q, et al. (1997) IGF-II stimulates cell proliferation through the insulin receptor. Proc Natl Acad Sci USA 94: 3777-3782

23. Ogata ES, Sabbagha R, Metzger BE, et al. (1980) Serial ultrasonography to assess evolving fetal macrosomia. J Am Med Assoc 243: 2405-2408

24. Tyrala EE (1996) The infant of the diabetic mother. Obstet Gynecol Clin North Am 23: 221-241

25. Rubin CS, Hirsch A, Fung C, Rosen OM (1978) Development of hormone receptors and hormonal responsiveness in vitro. Insulin receptors and insulin sensitivity in the prea- dipocyte and adipocyte forms of 3T3-L1 cells. J Biol Chem 253: 7570-7578

26. Smith PJ, Wise LS, Berkowitz R, Wan C, Rubin CS (1988) Insulin-like growth factor-I is an essential regulator of the differentiation of 3T3-L1 adipocytes. J Biol Chem 263: 9402-9408

27. Di Cola G, Cool MH, Accili D (1997) Hypoglycemic effect of insulin-like growth factor-1 in mice lacking insulin receptors. J Clin Invest 99: 2538-2544

28. Accili D, Taylor SI (1991) Targeted inactivation of the insulin receptor gene in mouse 3T3-L1 fibroblasts via homologous recombination. Proc Natl Acad Sci U S A 88: 47084712

29. Brunzell JD, Chait A (1990) Lipoprotein pathophysiology and treatment In: Rifkin H, Dorte DJ (eds) Ellenberg and Rifkin's diabetes mellitus. Elsevier, New York pp. 756-768

30. Girard J, Ferre P, Pegorier JP, Duee PH (1992) Adaptations of glucose and fatty acid metabolism during perinatal period and suckling-weaning transition. Physiol Rev 72: 507562

31. Pegorier JP, Prip BC, Duee PH, Girard J (1992) Hormonal control of fatty acid oxidation during the neonatal period. Diabete Metab 18: 156-160 